\title{
ADESÃO DAS ACADÊMICAS DE ENFERMAGEM À PREVENÇÃO DO CÂNCER GINECOLÓGICO: DA TEORIA À PRÁTICA ${ }^{1}$ NURSING STUDENTS' ADHESION TO GYNAECOLOGICAL CANCER: FROM THEORY TO PRACTICE \\ LA ADHESIÓN DE LAS ACADÉMICAS DE ENFERMERÍA A LA PREVENCIÓN DEL CÁNCER GINECOLÓGICO: DE LA TEORÍA A LA PRÁCTICA
}

\author{
Alessandra Bonato Beghini², Anna Maria de Oliveira Salimena 3 , Maria Carmen Simões Cardoso de Melo", \\ Ívis Emilia de Oliveira Souza $a^{5}$
}

${ }^{1}$ Pesquisa realizada como Trabalho de Conclusão do Curso de Graduação em Enfermagem.

${ }^{2}$ Enfermeira. Graduada no $2^{\circ}$ semestre de 2005 do Curso de Enfermagem da Faculdade de Enfermagem da Universidade Federal de Juiz de Fora (FACENF/UFJF).

${ }^{3}$ Mestre em Enfermagem. Doutoranda do Programa de Pós-Graduação da Escola de Enfermagem Anna Nery da Universidade Federal do Rio de Janeiro (EEAN/UFRJ). Professora Adjunto do Departamento Enfermagem Aplicada da FACENF/UFJF. Pesquisadora do Núcleo de Pesquisa em Enfermagem em Saúde da Mulher (NUPESM) da EEAN/UFRJ. Orientadora da Pesquisa.

${ }^{4}$ Mestre em Enfermagem. Professora Assistente do Departamento Enfermagem Aplicada da FACENF/UFJF. Co-Orientadora da Pesquisa.

${ }^{5}$ Doutora em Enfermagem. Professora Titular de Enfermagem Obstétrica do Departamento Enfermagem Materno- Infantil da EEAN/UFRJ. Pesquisadora e Membro da Diretoria do NUPESM/EEAN/UFRJ.

PALAVRAS-CHAVE: Enfermagem. Saúde da mulher. Prevenção de câncer de mama. Prevenção de câncer de colo uterino.

KEYWORDS: Nursing. Women's health. Breast cancer prevention. Cervix neoplasms prevention.

PALABRAS CLAVE: Enfermería. Salud de las mujeres. Prevención de cáncer de mama. Prevención de cáncer de cuello uterino.
RESUMO: Este estudo de natureza qualitativa, objetivou investigar no cotidiano das discentes do Curso de Graduação em Enfermagem, a adesão à prevenção do câncer cérvico-uterino e de mama. A obtenção dos dados se deu através de entrevista aberta a 41 acadêmicas de sétimo e oitavo períodos no segundo semestre de 2005. A análise de suas falas, apontou três categorias: conhecimento, atitude e prática; a dicotomia entre o saber e o fazer incorretamente; a dicotomia entre o saber e o não fazer. Revelou-se que a preconização do Ministério da Saúde quanto a este autocuidado é implementada corretamente por algumas das participantes, porém não o é por outras. Observou-se que o conhecimento adquirido no decurso das disciplinas não impõe nas acadêmicas a aderência de na prática, cuidar da própria prevenção. $\mathrm{O}$ tema mostrou-se bastante amplo e passível de reflexões, apresentando subsídios para novos questionamentos.

ABSTRACT: This qualitative study was developed and sought to investigate the day-to-day of Undergraduate Nursing students of the Federal University of Juiz de Fora, Brazil, and their adhesion to avoid cervix-uterine and breast cancer. The data was collected through open interviews with 41 seventh and eighth semester students during the second semester of 2005. The analysis of their answers pointed out three categories: knowledge, attitude and practice; the dichotomy between knowledge and incorrect action; and the dichotomy between knowledge and non-action. It became clear that the Ministry of Health's orientation about this self-care is correctly implemented by some students, but not by others. The knowledge acquired through taking classes was observed to not impose upon the students an adherence in care practice for their own prevention. This subject proved itself to be very ample, with many possibilities for reflection and further questions.

RESUMEN: Este estudio de naturaleza cualitativa, tuvo como objetivo investigar el cotidiano de las estudiantes del Curso de Graduación en Enfermería, su adhesión en la prevención del cáncer de cuello uterino y de mama. La obtención de los datos se dió a través de la entrevista abierta a 41 académicas de séptimo y octavo período en el segundo semestre de 2005. El análisis de sus declaraciones apuntó tres categorías: conocimiento, actitud y práctica; la dicotomía entre el saber y el hacer incorrectamente; la dicotomía entre el saber y el no hacer. Se reveló que la preconización del Ministerio de la Salud cuanto a este autocuidado, es implementada correctamente por algunas de las participantes, sin embargo, no siendo así por algunas. Se observó que el conocimiento adquirido en el decurso de las disciplinas no impone en las académicas la adherencia en la práctica el hecho de cuidar de la propia prevención. El tema se mostró bastante amplio y abierto a las reflexiones, presentando subsidios para nuevas interrogaciones.
Endereço: Alessandra Bonato Beghini R. Marechal Cordeiro de Faria, 172 36.081-330 - Carlos Chagas, Juiz de Fora, MG. E-mail: annasalimena@terra.com.br
Artigo original: Pesquisa Recebido em: 17 de maio de 2006. Aprovação final: 26 de outubro de 2006. 


\section{INTRODUÇÃO}

No decurso da Graduação em Enfermagem, muitas são as oportunidades de aprendizado das questões relativas à promoção da saúde e prevenção das doenças. No que se refere ao câncer, são obtidos, entre outros, conhecimentos referentes à morfologia $\mathrm{e}$ alterações celulares e anatomo-fisio-patologia, sendo abordadas as ações de prevenção e detecção precoce do câncer cérvico-uterino, mama, pele, boca, próstata, fatores de risco e os diversos tipos de auto-exame. Os conteúdos contribuem para a aproximação de vários aspectos do processo do cuidar na enfermagem oncológica, que vem permitindo ampliar e reforçar os conhecimentos sobre o tema.

Durante aulas práticas, realizadas em Unidade Básica de Saúde (UBS), algumas conversas informais entre as discentes sugeriam que talvez a prática $\mathrm{da}$ prevenção e detecção precoce do câncer, não estivesse sendo realizada pelas mesmas, da forma preconizada pelo Ministério da Saúde (MS). Este pensamento se reforçou ao analisar e confrontar criticamente o saber adquirido referente a este autocuidado e a implementação deste em nosso cotidiano.

Assim, ao refletir sobre o tema a ser abordado na elaboração da monografia de conclusão de curso, tornou-se instigante e envolvente investigar aspectos da prevenção do câncer cérvico-uterino e de mama pela mulher. Na perspectiva de pesquisar um tema que envolvesse a saúde e a enfermagem, ao discutir em orientação a temática, foi sugerido desenvolver o estudo entre as acadêmicas de enfermagem. Este aspecto evidenciou-se como relevante, ao se pretender confrontar o saber adquirido e sua aplicação na vivência das participantes, como fonte inspiradora e motivadora de aquisição ou mudança de hábitos relativos à prevenção da doença. Neste sentido, optou-se por serem depoentes as alunas de um curso de graduação em enfermagem que já tivessem cursado as disciplinas onde são trabalhados os conteúdos mais específicos de oncologia.

O câncer vem sendo considerado um importante problema de saúde pública, em razão de seus elevados índices, representando no Brasil, "a segunda causa de morte por doença, precedido apenas pelos agravos cardiovasculares".:17

Além da magnitude do problema ratificada pelos números elevados de sua incidência, prevalência e mortalidade, cabe ressaltar o sofrimento que a patologia acarreta, em especial o câncer de mama, que é a neoplasia maligna de maior ocorrência entre as mulheres em muitos países, representando no Brasil, dependendo da região considerada, a primeira ou a segunda mais freqüente. Esta forma da doença poderá refletir nos mais diversos aspectos da mulher, como já foi destacado: "A mama representa para a mulher várias formas de expressão de sentimentos. Ela traduz em si e por si toda uma simbologia ligada à maternidade, sexualidade e estética" 2:57

Apesar de ser este, um tipo de câncer considerado relativamente de bom prognóstico, é necessário para tanto que seja diagnosticado e tratado adequadamente, em etapa inicial. As modalidades terapêuticas nos estágios iniciais da doença, são menos mutiladoras e invasivas, representando na maioria dos casos, boas possibilidades de recuperação e cura.

O diagnóstico da doença já em fase avançada, vem sendo apontado como a provável causa dos seus altos índices de mortalidade. Reforçam esta possibilidade, os dados disponibilizados pelos Registros Hospitalares do Ministério da Saúde/Instituto Nacional do Câncer, no período de 2000/2001, ao apontar que " $50 \%$ dos tumores de mama foram diagnosticados nos estágios III e IV". 3:31

O câncer de colo de útero está em segundo lugar entre as mulheres no mundo, evidenciando-se a partir dos 20 anos. Seu risco aumenta rapidamente em torno dos 29 anos atingindo sua culminância entre 45 e 49 anos. "Atualmente, $80 \%$ dos casos novos surgem nos países em desenvolvimento sendo o mais comum entre as mulheres, em algumas regiões menos desenvolvidas destes".

A prevenção dessa doença tem sua relevância acentuada, não só por estes índices apontados, mas pelos importantes agravos que poderá ocasionar na mulher, quando diagnosticado e tratado tardiamente. Nesta condição, será afetada sua capacidade reprodutiva o que poderá interferir em sua sexualidade, com prováveis danos psicológicos ao atingir sua condição feminina. ${ }^{4}$

Dentre todos os tipos de câncer, o de útero e o de mama são os que apresentam um dos mais altos potenciais de detecção precoce, ressaltando-se assim, a importância das mulheres realizarem exames ginecológicos de rotina, como o auto-exame das mamas, o exame clínico das mamas e o exame Papanicolaou, que poderiam ser muito mais eficazes.

Apesar disto, as estimativas sobre sua incidência, apontavam para o ano de 2005 no Brasil, 49.470 casos de câncer de mama, com um risco estimado de 53 casos a cada 100 mil mulheres e 20.690 casos 
de câncer de útero, com um risco estimado de 22 casos a cada 100 mil mulheres. ${ }^{3}$

Em relação ao câncer de mama, alguns fatores ambientais ou comportamentais têm sido atribuídos a um maior risco de desenvolver a doença, porém os dados epidemiológicos até então identificados, não apontam evidências significativas que justifiquem ações exclusivas neste sentido. "A obesidade e o tabagismo parecem ser relevantes neste contexto, assim as ações de prevenção primária preconizadas são aquelas já estabelecidas em uma abordagem mais abrangente que contempla aspectos promotores da saúde no panorama das doenças crônicas não transmissíveis". 5:7

O controle do câncer depende essencialmente de ações na área da promoção da saúde, proteção específica e do diagnóstico precoce da doença. Segundo o Ministério da Saúde, as ações de prevenção secundária abrangem o "conjunto de ações que permitem o diagnóstico precoce da doença e o seu tratamento imediato, aumentando a possibilidade de cura, melhorando a qualidade de vida e a sobrevida, diminuindo a mortalidade por câncer”. 1:85

Nesta perspectiva, torna-se de grande importância para o seu diagnóstico, o exame das mamas, feito mensalmente pela própria mulher e realizado pelo profissional de saúde capacitado, no decurso de uma consulta, que pode ser de rotina ou não. Neste sentido, é também “imperioso o investimento de todos na prevenção do câncer, mas sobretudo daqueles que têm como dever fornecer serviços que contribuam para a promoção e manutenção da saúde, prevenção da doença e bem-estar das pessoas". ${ }^{6: 247}$

A detecção do tumor da mama tem sido realizada através de três procedimentos específicos: o auto-exame das mamas (AEM), o exame clínico das mamas (ECM), e a mamografia. A motivação para o AEM vem sendo recomendada por sua utilidade, inexistência de custo e de efeitos adversos, principalmente ao se comparar os benefícios que podem advir de sua adoção no cotidiano das mulheres. Sua execução, embora de grande relevância contribuindo também para o autoconhecimento, não exclui a sua complementação pela prática do ECM realizada por profissional de saúde. ${ }^{1}$ Este é apontado como "parte do atendimento integral à saúde da mulher, devendo, ser realizado em todas as consultas clínicas, independente da faixa etária". 5:7 Recomenda-se, a partir de 35 anos, que as mulheres pertencentes a grupos considerados de risco, devem submeter-se anualmente ao ECM e à mamografia, e para as mulheres em geral, estes devem ter um intervalo de no máximo dois anos, na faixa etária entre 50 a 69 anos. $^{5}$

O enfermeiro pode prestar importante contribuição para a prevenção do câncer de colo uterino, destacando-se, dentre outras, sua participação no controle de fatores de risco, na realização da consulta ginecológica e do exame de Papanicolau, influindo para um maior e melhor atendimento à demanda, efetivando um sistema de registro de qualidade, intervindo para o encaminhamento adequado das mulheres que apresentarem alterações citológicas. ${ }^{1}$

O governo brasileiro, incentivado pela Conferência Mundial de Mulheres realizada em Pequim na China em 1995, desenvolveu o Programa Viva Mulher, que consiste no desenvolvimento e na prática de estratégias que reduzam a mortalidade e as repercussões físicas, psíquicas e sociais do câncer do colo do útero e de mama. Sabemos que, por meio de uma ação conjunta entre o Ministério da Saúde e todos os 26 estados brasileiros, além do Distrito Federal, são oferecidos serviços de prevenção e detecção precoce em estágios iniciais da doença, assim como tratamento e reabilitação em todo território nacional.

O envolvimento da enfermagem nas questões referentes ao câncer se dá na medida em que, na atualidade, este se refere a um problema de saúde pública, face à "sua magnitude (elevada morbimortalidade) e transcendência (alto custo social e econômico)"..$^{1: 90}$ Neste sentido, torna-se imprescindível o adequado preparo da equipe de enfermagem para as demandas do cuidar desta clientela. O enfermeiro é o profissional responsável pelo processo educativo desta equipe, sendo de sua competência divulgar informações à clientela, no tocante aos fatores de risco, ações de prevenção e detecção precoce, orientando e adotando para si modelos de comportamento e hábitos saudáveis". ${ }^{1}$

Durante sua formação, o profissional de saúde se apropria de conhecimentos que lhe serão úteis no decorrer de sua prática. Espera-se que este saber adquirido, seja por ele incorporado, adotado e implementado também em seu cotidiano pessoal.

Sobre a importância deste olhar para si e identificar as necessidades próprias ressalta-se que "o ser que cuida necessita ser cuidado e estimulado a desbravar as fronteiras do cotidiano 
entrando em contato consigo mesmo, com suas potencialidades, com seus recursos e possibilidades" 7:368 Assim, este ser que cuida do outro, ao ir em busca de si mesmo através do vivenciado em experiências pessoais ou profissionais, procura " $\mathrm{O}$ sentido e o significado do cuidar/ cuidado em enfermagem, lembrando a todos que ele, enquanto ser, necessita também de cuidado". 7:368

Sobre as vantagens e desvantagens da utilização do AEM, o Ministério da Saúde enfatiza que este deve ser divulgado e incentivado, porém aponta ser possível a ocorrência de exames falsos negativos que resultariam para a mulher em uma inadequada segurança, e, achados falsos positivos, que podem gerar ansiedade desnecessária. Correlaciona em parte esta condição de incorreção, a "destreza adquirida pela mulher para praticar o AEM, e a aprendizagem dela, por sua vez, depende da maneira como ela é orientada e de todos os condicionantes que envolvem o processo ensino-aprendizagem". 1:111

As acadêmicas do Curso de Graduação em Enfermagem, ao assumirem uma postura de cuidar de si, além de aprimorar seu saber técnico-científico e habilidades, consolidam o conhecimento adquirido. Esta conduta poderá lhes proporcionar maior segurança na realização de consultas propiciando-lhes melhor desenvoltura no relacionamento com suas pacientes. A inserção do profissional em uma organização de prestação de cuidados, torna-o responsável por um atendimento humanizado e de qualidade. A atitude de promoção da sua saúde irá contribuir positivamente não só no que diz respeito à saúde do próprio profissional, mas com certeza, fortalecerá sua destreza, aptidão e conhecimentos, refletindo em um atendimento de excelência à clientela.

No que se relaciona à prevenção do câncer, cabe às futuras enfermeiras, sua mobilização, envolvimento e prática, tanto na assistência à clientela, quanto em sua conscientização da necessidade de efetuar regularmente o AEM, o ECM e o Exame Papanicolau, conforme preconizado.

Sendo assim, considerando a importância da prevenção e tendo inquietações sobre a sua realização, o estudo foi desenvolvido a partir da questão norteadora: como as discentes do Curso de Graduação em Enfermagem têm se comportado frente à adesão ao exame de prevenção do câncer ginecológico (mama e cérvico-uterino)? Após cursarem disciplinas teóricas e práticas que abordam o assunto, este saber é incorporado em seu cotidiano passando a ser adotado como prática de autocuidado?

\section{OBJETIVO DO ESTUDO}

Investigar a prática de prevenção do câncer ginecológico entre as acadêmicas de enfermagem analisando aspectos favoráveis ou limitadores.

\section{TRAJETÓRIA METODOLÓGICA}

A abordagem qualitativa do assunto se evidenciou como sendo adequada para a análise das vivências relatadas pelas participantes, propiciando a aproximação da compreensão tanto de aspectos objetivos como também daqueles particulares e subjetivos, pois que: "a abordagem qualitativa aprofunda-se no mundo dos significados das ações e relações humanas, um lado não perceptível e não captável em equações, médias e estatísticas". $8: 22$

Ao aprofundar conhecimentos sobre pesquisas qualitativas, encontrou-se respaldo na afirmativa que destaca: "a atividade de ensino a atualiza frente à realidade do mundo. Portanto, embora seja uma prática teórica, a pesquisa vincula pensamento e ação, o foco de interesse é amplo e parte de uma perspectiva diferenciada da adotada pelos métodos quantitativos" 8:17

Conforme o estabelecido pelas normas legais que respaldam a pesquisa envolvendo seres huma-

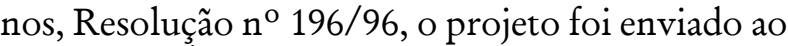
Comitê de Ética em Pesquisa da UFJF, tendo sido aprovado por este Órgão. ${ }^{9}$

Foram sujeitos deste estudo, discentes do sexo feminino, regularmente matriculadas para o $2^{\circ}$ semestre letivo de 2005, após a autorização da Diretora da Unidade Acadêmica. Após conhecimento e anuência das discentes cursando os períodos acima definidos, foram realizadas entrevistas com 41 acadêmicas, com faixa etária de 22 a 30 anos, no período de agosto de 2005 e janeiro de 2006.

Os dados foram coletados a partir de entrevistas abertas, pois, “[...] a entrevista é o procedimento mais usual no trabalho de campo. Através dela, o pesquisador busca obter informações contidas na fala dos atores sociais". ${ }^{10: 57}$

As perguntas: o que você faz e como faz a prevenção do câncer cérvico-uterino e de mama? Quando você realizou o último preventivo? Estas perguntas deram ampla possibilidade de manifestação livre das participantes e propiciaram a aquisição de significados voltados aos objetivos do estudo. Foram gravadas e transcritas posteriormente e para manter o anonimato as entrevistas foram numeradas de acordo com a seqüência realizada. 
Para construção das categorias utilizou-se a análise de conteúdo.

\section{ANÁLISE DOS DEPOIMENTOS}

Seguindo os passos preconizados, que definem como se deve proceder à análise compreensiva dos depoimentos, "as informações obtidas foram relacionadas com literatura referente ao tema, traçando os pontos centrais de forma a analisá-los”. 12: 21

Deste exercício de organização das asserções significativas surgiu então a seguinte distribuição dos depoimentos e as expressões que foram assim denominadas: conhecimento, atitude e prática; a dicotomia entre o saber e o fazer incorretamente; a dicotomia entre o saber e o não fazer.

\section{Conhecimento, atitude e prática}

Entre as alunas entrevistadas é reconhecida a necessidade de realizar a prevenção do câncer cérvico-uterino e de mama, assim como a sua periodicidade e a forma correta de fazerem tal prevenção. Elas anualmente procuram um profissional especializado para realizar o exame de colpocitologia oncótica ou Papanicolau. [...] o câncer cérvico-uterino eu faço a prevenção através do exame preventivo com consultas anuais com o ginecologista. E... consultas anuais! (E $\left.E_{27}\right) ;$.... Faço preventivo todo ano e se tiver algum problema repetir em seis meses! $\left(E_{30}\right)$.

Com relação ao auto-exame das mamas, algumas se mostraram bastantes preocupadas, se palpam, observam alguma anormalidade, procuram seu bem estar físico com ausência de patologias. $\mathrm{O}$ exame das mamas realizado pela própria mulher ajuda no conhecimento de seu corpo, mas não deve ser usado isoladamente. A mulher deverá procurar um profissional especializado para a realização do exame clínico das mamas e este solicitará, se necessário, os exames complementares para investigação de alguma suspeita. [...] o de mama além de fazer durante o preventivo, porque eu faço anual, en faço também o toque a cada mês após 10 dias da menstruação $\left(\mathrm{E}_{21}\right)$.

A freqüência e a forma como é realizado o exame torna mais fácil notar qualquer modificação nas mamas de um mês para o outro. Os diversos autores assinalam que mulheres praticantes do autoexame das mamas tendem a ter diagnóstico com tumores primários menores, quando comparadas com as que não praticam. É importante que estas mulheres não percam o hábito e não esqueçam de realizar o auto-exame.
A dicotomia entre o saber e o fazer incorretamente

As alunas afirmam realizar a prevenção, porém não o fazem como o preconizado. Foram identificados vários erros com relação à periodicidade e maneira como efetivam este autocuidado, o que poderá ser confirmado nas falas que se seguem: [...] realizo o auto-exame das mamas durante o meu periodo menstrual $[. .].\left(E_{21}\right) ;[. .$.$] eu costumo fazer o toque na mama,$ mas quando eu lembro! Não é sempre $\left(E_{2}\right) ;[. .$.$] eu não faço$ isso regularmente de jeito nenbum, é só mesmo quando eu lembro, quando a gente vai fazer algum trabalho educativo onde a gente está educando para isso e aí a gente para e pensa: e ai eu estou fazendo? Ai você pensa um pouco, aí você faz... $\left(E_{25}\right)$. A periodicidade aqui evidenciada, mostra-se muito variável e discordante das orientações sobre o tema. Também foi relevante a dificuldade demonstrada pelas discentes, ao expor sua prática cotidiana. As mesmas demonstraram vergonha pelo esquecimento, e insegurança durante as falas ao descrever como é realizada a prevenção. A preocupação e a ocupação com as tarefas e atividades a serem desenvolvidas em sua condição de acadêmicas é apontada como sendo a razão para o esquecimento e não efetivação sistemática da prevenção do câncer ginecológico, conforme preconizado. ${ }^{1}$

Como futuras enfermeiras, as acadêmicas devem realizar corretamente os procedimentos preconizados, pois já adquiriram o saber que dá suporte à prática, ao cursarem as disciplinas referidas anteriormente. A aquisição de habilidades a partir da execução sistematizada pode interferir positivamente na aptidão, resultando em benefício tanto para o cuidar de si, quanto para o dispensado à clientela.

Medidas preventivas devem ser intensificadas para a diminuição dos fatores de risco, bem como para diagnóstico e tratamento precoce do câncer. Há preocupação manifesta por algumas alunas em adotar os procedimentos preventivos preconizados. Encontra-se descrita na literatura a forma de execução do auto-exame das mamas, ressaltando que o mesmo poderá ser "realizado na hora do banho, com a pele ensaboada, para facilitar o deslizamento dos dedos”. ${ }^{13: 88}$

Com relação à prevenção do câncer cérvicouterino a maioria das alunas entrevistadas realiza de forma correta. Foi observado nesta categoria o aumento do intervalo entre o último exame preventivo realizado e o exame atual. O emprego 
da colpocitologia em periodicidade anual reduz a probabilidade de uma mulher desenvolver câncer invasivo, daí a importância de se manter os intervalos preconizados.

\section{A dicotomia entre o saber e o não fazer}

A não realização da prevenção do câncer poderá acarretar danos à própria mulher. Dentre as participantes do estudo, embora sejam constadas incorreções, não se detectou a total inexistência deste agir. Algumas executam a prevenção do câncer de mama e não realizam a prevenção do câncer cérvico-uterino por alguns motivos que serão descritos a seguir, outras realizam a prevenção do câncer cérvico-uterino e não realizam a prevenção do câncer de mama.

A ênfase dada ao autocuidado trata-se de ponto de primordial importância. Ressaltando que este exame pode ser facilmente realizado pela própria pessoa e se detectada alguma alteração, então, deve-se procurar ajuda em serviço especializado, onde será pesquisada a existência da doença em fase precoce possibilitando, assim, melhor prognóstico. ${ }^{2}$ É... sobre o câncer cérvico-uterino, eu nunca fiz. nenhum método para prevenir, porque como eu nunca tive relação sexual e então nunca fizo o exame preventivo, então eu não previno. E sobre o câncer de mama é... apesar de saber da importância de como se faz o exame, não faço periodicamente, é só quando eu lembro, às vezes, assim uma vez ou outra faço $\left(E_{24}\right)$.

Esta outra aluna que também nunca teve relação sexual ressalta a importância de efetivar este cuidar: com relação ao câncer cérvico-uterino eu faço consulta ginecológica de ano em ano e pelo fato de eu não ter relação sexual o meu preventivo ele é simplesmente com um cotonete $[. .].\left(\mathrm{E}_{11}\right)$.

A não realização do exame de Papanicolau está associada à vida pessoal da aluna. Entre aquelas que nunca tiveram relações sexuais, ocorre a alegação de não sentirem a necessidade de realizar o exame. Tal afirmativa não tem apoio na literatura pois, mesmo diante desta condição, este é indicado, apenas ocorrendo de forma diferenciada daquela utilizada quando se possui vida sexual ativa.

O exame ginecológico é um dos mais importantes exames para a saúde da mulher. É normal que existam medos e ansiedades para sua realização, porém trata-se de um exame simples que tem influído na redução das mortes por câncer de colo de útero. Todas as mulheres com ou sem atividade sexual devem fazer o exame anualmente. A realização do exame citopatológico de Papanicolau tem sido re- conhecida mundialmente como estratégia segura e eficiente para a detecção precoce do câncer do colo de útero na população feminina e tem modificado efetivamente as taxas de incidência e mortalidade por este câncer. ${ }^{1}$ Segundo o Ministério da Saúde, o "[...] exame colpocitológico (Papanicolau) apresenta alta eficácia para o diagnóstico precoce, além de ser um método aceito pela população e comunidade científica, seguro, de fácil execução, não invasivo e de baixo custo". 1:124

A promoção de conhecimentos a respeito do próprio corpo e da importância de se submeter a tal exame fornece subsídios para que as alunas identifiquem o que é melhor para si, conforme expressa esta fala: [...] bom, assim... eи não faço, não eu não faço!... assim para prevenir o câncer cérvico-uterino, assim, eu já fui no ginecologista e tal, faço acompanhamento e tudo, mas assim de ano em ano, e o câncer de mama, assim, quando eu vou no ginecologista ela faz. o auto exame, mas eu mesma fazer é muito raro... é ate meio contraditório, porque a gente orienta as mulheres para fazer e na realidade não faz né?... mas assim, é um caso até a se pensar $\left(E_{23}\right)$.

Este depoimento demonstra a importância percebida das condutas preventivas preconizadas, e embora esta, não tenha efetivado a sua adoção, demonstra conhecimento do tema. Este processo depende da participação ativa e da decisão da mulher que, a partir da compreensão e interpretação, tem a possibilidade de ser responsável pela sua saúde, neste aspecto.

Promover ações sabidamente benéficas à saúde é uma forma de prevenir o aparecimento do câncer. [...] eu faço preventivo anualmente, não costumo fažer o auto-exame das mamas e realizei o último preventivo acho que em outubro do ano passado e o exame das mamas junto com o preventivo. Não sou en que faço o exame das mamas porque en não sei fazer $\left(E_{2 \sigma}\right)$. Embora afirme não saber fazer o auto-exame das mamas, como estudante do curso de enfermagem regularmente matriculada no $8^{\circ}$ período, recebeu informações neste sentido.

O saber ou não saber está diretamente relacionado ao fazer com freqüência, se há o hábito de fazer rotineiramente, dificilmente esquecerá a técnica recomendada. A não execução poderá prejudicar a incorporação deste conhecimento e interferir na melhoria da sua qualidade de vida e, futuramente, na assistência prestada aos seus pacientes.

Necessário é apontar também, a existência do medo de descobrir alguma anormalidade, e a insegurança de realizar o exame preventivo. $O$ medo de ser 
portador da doença afasta a paciente do diagnóstico e determina a diferença de resultados terapêuticos que chegam a quase $100 \%$ de cura nas lesões iniciais e caem para menos do que $30 \%$ nas lesões avançadas. ${ }^{1}$

Ao abordar o medo provocado pela ameaça de perda, encontra-se respaldo na seguinte exposição: "o medo é definido como uma fuga do perigo, mas a situação essencial para o seu aparecimento é a percepção de uma condição de ameaça e de perigo". 14:48

Muita coisa evoluiu na área de oncologia e saúde da mulher, porém o comportamento social continua o mesmo, com a doença sendo vista como algo impuro que deva ser escondido. Essa atitude deve mudar e o medo exacerbado da doença deve dar lugar a uma postura correta em relação à adoção das práticas preventivas preconizadas. Porém, este temor precisa ser dimensionado em sua plenitude, pois não se trata apenas de um tabu.

O medo que se contrapõe à realização do exame preventivo para câncer é algo que precisa ser entendido em toda a sua dimensão de forma mais abrangente e aprofundada. Nesta perspectiva, ao fazer uma análise compreensiva das falas de mulheres sobre a prevenção do câncer cérvico-uterino, fundamentadas em Heidegger, expõem sua compreensão de que "o temor em suas diferentes variações" vivenciado pelas mulheres na situação de exame ginecológico pode se apresentar assim dimensionado: "o pavor de algo conhecido, o exame e a possibilidade do câncer; o horror do não familiar, a rotatividade de profissionais; e o terror de algo súbito e desconhecido, a vivência da doença". 15: 60

\section{CONSIDERAÇÕES FINAIS}

O desenvolvimento do presente estudo foi direcionado para a verificação de adesão das acadêmicas de enfermagem à prevenção do câncer ginecológico. A análise evidenciou que as alunas do período mais avançado do Curso se mostraram mais conscientes e possuindo melhor conhecimento a respeito da prevenção do câncer cérvico-uterino e de mama do que as alunas do período anterior. Tal aspecto pode ser atribuído ao fato de estarem vivenciando, neste momento, atividades práticas de realização de consultas em suas pacientes incluindo o ECM, coleta de material para o exame Papanicolau e ações educativas para as mulheres adotarem o auto-exame das mamas. As que estão cursando o período anterior, neste momento não têm a oportunidade de praticarem a prevenção do câncer, a não ser em si mesmas, e como na maioria das vezes isso não acontece sistematicamente, acaba resultando no distanciamento dos conhecimentos teóricos e práticos adquiridos ao longo do curso.Também são aspectos relevantes: o medo de encontrarem alguma anormalidade e a insegurança em realizar os procedimentos.

Grande parte das entrevistadas reconhece a necessidade da colpocitologia, com a sua periodicidade e realiza a prevenção corretamente. Algumas apontaram a não execução do procedimento por não possuírem vida sexual ativa e, apenas uma, disse realizar o exame preventivo quando encontra alguma anormalidade e não rotineiramente como as demais.

Em relação à execução e freqüência do AEM a maioria não se manifestou para a incorporação dessa prática, embora reconhecendo que esta postura é importante para a detecção precoce do câncer de mama em estágios iniciais. Observa-se que entre as que o realizam, algumas não obedecem ao procedimento técnico conforme preconiza o Ministério da Saúde, aumentando assim, consideravelmente, as chances de encontrarem algum nódulo em estágio avançado.

Diante do exposto, ainda existiriam muitas discussões e novos questionamentos sobre o tema, na tentativa de lançar mais luz em direção à melhoria dos indicadores de câncer ginecológico. Para que isto aconteça deve ser repensada a prática discente, criando hábitos de realização de exames preventivos, melhorando o estilo de vida, estudando sempre as inovações a respeito do tema, envolvimento no cuidar de si para cuidar da saúde das clientes mulheres com mais segurança, dignidade, sabedoria, humanização e o mais importante, com amor.

Espera-se que a divulgação dos resultados desta pesquisa possa trazer contribuições às reflexões entre os profissionais de enfermagem, docentes e acadêmicas do curso de Enfermagem.

\section{REFERÊNCIAS}

1 Ministério da Saúde (BR), Instituto Nacional do Câncer. Ações de Enfermagem para o controle do câncer: uma proposta de integração ensino-serviço. 2a ed. Rio de Janeiro (RJ): INCA; 2002.

2 Melo MCSC. Refletindo em um contexto: a mulher e o auto-exame da mama [dissertação]. Rio de Janeiro (RJ): UFRJ/EEAN/Programa de Pós-Graduação em Enfermagem; 1992. 
3 Ministério da Saúde (BR), Secretaria de Atenção à Saúde, Instituto Nacional do Câncer, Coordenação de Prevenção e Vigilância. Estimativa 2005: incidência de câncer no Brasil. Rio de Janeiro (RJ): INCA; 2004.

4 Souto MD, Souza IEO. Sexualidade da mulher após a mastectomia. Escola Anna Nery Rev. Enferm. 2004 Set-Nov; 8 (3): 402-10.

5 Ministério da Saúde (BR), Secretaria de Atenção à Saúde, Instituto Nacional do Câncer, Coordenação de Prevenção e Vigilância. Controle do câncer de mama: documento de consenso. Rio de Janeiro (RJ): INCA; 2004.

6 Branco IMBHP. Prevenção do câncer e educação em saúde: opiniões e perspectivas de enfermagem. Texto Contexto Enferm. 2005 Abr-Jun; 14 (2): 246-9.

7 Bauer MR, Pinheiro PIG. Retrato de mulher: relações entre o cuidar e ser cuidada. Texto Contexto Enferm. 1998 Mai-Ago; 7 (2): 366-84.

8 Minayo MCS, organizadora. Pesquisa social: teoria, método e criatividade. $22^{\mathrm{a}}$ ed. Petrópolis (RJ): Vozes, 2003.

9 Ministério da Saúde (BR), Conselho Nacional de Saúde, Comitê Nacional de Ética em Pesquisa em
Seres Humanos. Resolução No 196 de 10 de outubro de 1996: diretrizes e normas regulamentadoras de pesquisa envolvendo seres humano. Brasília (BR); O conselho; 1996.

10 Minayo MCS. O desafio do conhecimento: pesquisa qualitativa em saúde. 3a ed. São Paulo (SP)/Rio de Janeiro (RJ): Hucitec; 1995.

11 Bardin L. Análise de conteúdo. Lisboa (PT): Edições 70; 1995.

12 Martins J, Bicudo MAV. A pesquisa qualitativa em psicologia: fundamentos e recursos básicos. São Paulo (SP): Morais; 1989.

13 Santos F. Tire essa mágoa do peito. São Paulo: Ed. Gente; 1999.

14 Salimena AMO. Buscando compreender os sentimentos da mãe ao deixar o filho à porta da sala de cirurgia [dissertação]. Belo Horizonte (MG): UFMG/EE/ Programa de Pós-Graduação em Enfermagem; 2000.

15 Lopes RLM, Souza IEO. Repensando a prevenção do câncer cérvico-uterino através de uma abordagem compreensiva. Texto Contexto Enferm. 1997 JanAbr; 6 (1): 50-65. 